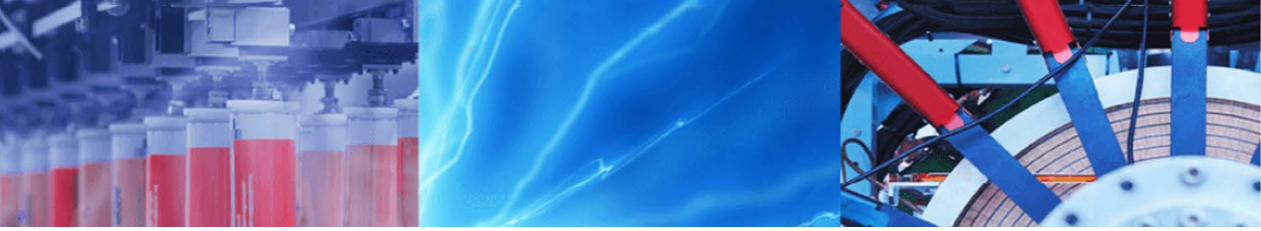

Research Article

\title{
Storage and thermal stability of biodiesel produced from manketti nut oil of Southern Africa origin with the influence of metal contaminants and antioxidants
}

\author{
Thomas Kivevele $e^{1,2,3}$ (D)
}

Received: 31 August 2019 / Accepted: 11 April 2020 / Published online: 20 April 2020

(c) Springer Nature Switzerland AG 2020

\begin{abstract}
Biodiesel has widely been produced from common edible oils; however, food versus fuel conflicts has motivated researchers to search for other less common feedstock for production of biodiesel. Thus, this study investigates the suitability of biodiesel made from less common manketti nut oil in terms of its thermal and long-term storage stability. Also, since biodiesel is stored in containers made of different metals; the influence of metal contaminants on the storage stability of biodiesel is also examined. Manketti Oil Methyl Ester (MOME) is synthesized by the transesterification process and characterized as per biodiesel global standards. MOME is doped with antioxidants (1, 2, 3 tri-hydroxy benzene (Pyrogallol, PY) and 3, 4, 5-tri hydroxy benzoic acid (Propyl Gallate, PG)) at different ratio to analyse its influence on the stability of MOME. Also, 2 ppm of selected metals ( $\mathrm{Co}, \mathrm{Cu}, \mathrm{Fe}, \mathrm{Mn}$, and $\mathrm{Ni}$ ) is doped to MOME samples with and without antioxidants and stored for 6 months in open and closed $500 \mathrm{ml}$ plastic bottles. Oxidation stability is measured once a month to monitor stability of MOME. Thermogravimetric analysis is conducted to examine thermal stability of MOME. The results show that freshly-synthesized MOME has oxidation stability of $4.24 \mathrm{~h}$ below the European EN 14214 (8 h) and South African SANS 1935 (6 h) standards. On adding antioxidant PY and PG at 200 ppm concentration, the oxidation stability increases to $13 \mathrm{~h}$ and $8.5 \mathrm{~h}$ respectively. The result of MOME contaminated with metals shows that $\mathrm{Cu}$ has the highest damaging effects on oxidation stability during storage. Additionally, thermal stability analysis results exhibit that MOME has excellent thermal stability of $211.33^{\circ} \mathrm{C}$.
\end{abstract}

Keywords Manketti oil $\cdot$ Thermal stability $\cdot$ Oxidation stability $\cdot$ Antioxidants $\cdot$ Metal contaminants

\section{Introduction}

Fossil fuels are non-renewable energy resources, which account for $78.3 \%$ of the world energy consumption, while renewables and nuclear power contribute 19.2\% and $2.5 \%$, respectively [1]. Due to massive worldwide energy demand, fossil fuel reserves are getting depleted faster than their rate of regeneration since it takes millions of years for them to form [2]. Fossil fuels are significantly responsible for increasing environmental issues such as emission of greenhouse gases, air pollution and global warming. Some of the emissions generated include $\mathrm{CO}$, $\mathrm{CO}_{2}$, NOx, unburnt or partially burnt $\mathrm{HC}$ and particulates. Thus, the challenges associated with using fossil fuels have motivated a search for potential alternative fuels, which are renewable and pose less risk to the environment [3]. In that regard, biodiesel has proven to be an ideal alternative fuel for petroleum-based diesel. Biodiesel, which

$\square$ Thomas Kivevele, kivevelethomas@gmail.com | 1 Department of Materials and Energy Science and Engineering, Nelson Mandela African Institution of Science and Technology (NM-AIST), P. O. Box 447, Arusha, Tanzania. ${ }^{2}$ African Centre of Excellence for Water Infrastructure and Sustainable Energy Futures (WISE-Futures), NM-AIST, P. O. Box 9124, Arusha, Tanzania. ${ }^{3}$ Department of Mechanical Engineering, Mechatronics and Industrial Design, Tshwane University of Technology, Private Bag X680, Pretoria 0001, South Africa. 
constitutes mono-alkyl esters, is synthesised by transesterification of animal fats, vegetable oils, algae and used cooking oils in presence of alcohol and a catalyst [4]. It is a clean-burning fuel, renewable, produces minimal toxic pollutants and greenhouse gases as compared to petroleum-based diesel when used in diesel engines [2-4].

Despite all the merits of biodiesel, it is more susceptible to oxidation in comparison with petroleum-based diesel when exposed to air, daylight, high-temperature conditions and metal contaminants $[4,5]$. However, biodiesel's level of oxidation depends on the type and location of feedstock, storage conditions and natural occurrence of antioxidants [4-7]. Various studies have addressed the issue of biodiesel oxidation stability based on different feedstock. They concluded that high unsaturated fatty acid content of esters is the primary reason for the susceptibility of biodiesel to oxidation [4-8].

The oxidation of biodiesel significantly affects its main fuel properties, for instance, kinematic viscosity, acid value and cetane number. Oxidized biodiesel possesses stable products, for example, aldehydes, insoluble gums, shorter carboxylic acids, peroxides, sediments and total acids. The presence of these products affects biodiesel quality and impairs the performance of engines. Besides, they result in injector fouling, plugging of fuel filters, and the formation of deposits in the engine combustion chamber and other fuel system components, which in turn damages the vehicle fuel systems $[4,5,7,9]$. Most of the available literature has reported the oxidation stability of edible oil-derived biodiesel [6]. However, due to food versus fuel conflicts, it is imperative to utilize alternative feedstock such as vegetable oils from less common tree born seeds which do not pose a threat to food security. Thus, this work investigates the suitability of biodiesel produced using manketti nut oil, which is obtained from less common and wildly-grown manketti plants $[9,10]$. The tree is widely distributed in Southern Africa. It prefers hot temperatures and little rain. It grows in the wild on sandy soils between the latitudes of 15 and $21^{\circ} \mathrm{S}$ in many parts of Botswana, South Africa, Zambia, Angola, Namibia and up to Mozambique [11]. It can be found in large stands, several hundred meters wide and stretching for several kilometres, across the well-drained Kalahari sands. Some countries such as Mauritania, Guinea, Liberia, Ethiopia, Sudan, Chad, Mali, Niger and Uganda are also suitable for the cultivation of Manketti tree [11]. The manketti tree was also introduced to Australia in the late 1980s [11].

Various studies have reported the potential of manketti oil for application in the cosmetic and nutraceutical industry. Cheikhyoussef et al. [9] characterized Schinziophyton rautanenii (Manketti) nut oil originating from Namibia. The collected manketti seeds yielded oil of about $42.6 \pm 0.84 \%$ and was rich in tocopherols and conjugated fatty acids.
Besides, unsaturated fatty acids, mainly linoleic acid (31-32\%) and linolenic acid (24-36\%) dominated in the oil. These unsaturated fatty acids tend to get oxidized though they are suitable for nutraceutical and cosmetics applications. Juliani et al. [10] assessed the properties of manketti cold-pressed oil and its potential for application in the cosmetic industry. Using a manual hand press, $28 \%$ of oil was extracted from the seeds while up to $38 \%$ of oil was obtained with a hydraulic press method. The report indicated that manketti oil had a high unsaturated fatty acid content recording $10 \mathrm{mg} / \mathrm{kg}$ peroxide value, $1.6 \%$ acid value, and $-7{ }^{\circ} \mathrm{C}$ solidification point.

There are limited studies regarding biodiesel production from manketti nut oil. Kivevele and Huan [12] investigated the potential of biodiesel synthesized from manketti oil as a substitute for petroleum-based diesel. Most of the fuel-related properties met the minimum requirements prescribed in global biodiesel standards (ASTM D6751 and EN 14214). The study, however, did not evaluate the effectiveness of the antioxidants on biodiesel stability during long-term storage under different conditions. Biodiesel typically contains limited amounts or no natural antioxidants at all, they become less stable over time; therefore, antioxidants need to be applied to the biodiesel during long-term storage [7, 12]. Rutto and Enweremadu [13] employed response surface methodology to optimize the production variables of biodiesel synthesized from manketti nut oil. They used an alkali catalysed transesterification process, and the optimum conditions reported are as follows: $55^{\circ} \mathrm{C}$ (reaction temperature), $53 \mathrm{~min}$ (reaction time), $1.02 \mathrm{wt} \%$ (amount of catalyst) and $32 \mathrm{wt} \%$ (amount of methanol in the oil). At these operating conditions, the optimum yield of Fatty Acid Methyl Esters (FAME) reported to be $98.3 \%$, and most of the essential fuel-related properties met the EN 14214, SANS 1935, and ASTM D6751 standards. Atabani et al. [11] studied production and characterization of Manketti (Ricinodendron rautonemii) methyl ester and its blends with diesel. The effect of Manketti biodiesel on engine and emissions performance was also investigated. The results showed that biodiesel had kinematic viscosity of about $8.34 \mathrm{~mm}^{2} / \mathrm{s}$ higher than the limit described by the ASTM D6751 and EN 14214. They explained that high kinematic viscosity of the parent oil contribubed to high kinematic viscosity of biodiesel. However, blending manketti methyl ester with diesel improved its kinematic viscosity, calorific value and density. For the engine tests, blending diesel with manketti methyl ester produced lower break power, increased brake specific fuel consumption, produced higher $\mathrm{CO}$ and $\mathrm{HC}$ emissions but significantly reduced $\mathrm{NO}$ emission compared to diesel fuel.

From the studies above, it can be seen that the longterm storage stability and thermal stability of biodiesel made from manketti nut oil at various conditions in the 
presence or absence of antioxidants are not extensively investigated. Moreover, biodiesel is stored in containers made of different metals, and it is quite possible that if biodiesel gets contaminated with metals its stability might be affected, but this has also not been investigated with regards to manketti methyl esters. Therefore, this study investigates the stability of biodiesel derived from less common manketti nut oil of Southern Africa origin in terms of thermal stability and long-term storage stability. Besides, the influence of metal contaminants such as $\mathrm{Co}$, $\mathrm{Cu}, \mathrm{Fe}, \mathrm{Mn}$, and $\mathrm{Ni}$ on storage stability of biodiesel is also studied. Understanding the stability of biodiesel is critical because autoxidation affects the quality of biofuels and damages vehicle fuel systems when oxidized biodiesel is used in the diesel engines.

\section{Materials and methods}

\subsection{Materials}

All chemicals utilized in the present research such as potassium hydroxide (85\%), which is in pellet form and methanol (99.5\%) are analytical grade and no further purification processes are undertaken. The chemicals and Manketti nut oil have all been purchased from the department of chemistry, Arcadia Campus, Tshwane University of Technology, South Africa. Diesel fuel used for comparison purposes with MOME in this study is obtained from local filling station in Pretoria, South Africa. The antioxidants such as 3, 4, 5-tri hydroxy benzoic acid (Propyl Gallate, PG) and 1, 2, 3 tri-hydroxy benzene (Pyrogallol, PY) are purchased from Alfa Aesar Company, German. Transition metals in powdered form ( $2 \mu \mathrm{m})$ such as $\mathrm{Co}, \mathrm{Cu}, \mathrm{Fe}, \mathrm{Mn}$, and $\mathrm{Ni}$ have been supplied by Africo Resources Limited, Cape Town, South Africa.

\subsection{Biodiesel production}

Manketti nut oil is tested for free fatty acid content (FFAs) using conventional AOCS (American Oil Chemists' Society) titrimetric method as described elsewhere $[14,15]$. The manketti nut oil recorded FFAs of about $1.85 \%$, which is below the recommended upper limit of $2 \%$. Therefore, only one step transesterification process is required in the production of manketti biodiesel [12]. Manketti oil is pre-heated at $110^{\circ} \mathrm{C}$ for $10 \mathrm{~min}$ to drive out moisture and later cooled to room temperature. The transesterification process (Fig. 1) of Manketti nut oil is then conducted using standard conditions based on previous works [12, $16,17]$. The process is carried out using $1.0 \mathrm{wt} \%$ potassium hydroxide, methanol/oil molar ratio of $6: 1$ at $60^{\circ} \mathrm{C}$ reaction temperature, 90 min reaction time, and $400 \mathrm{rpm}$ agitation speed. The effectiveness of antioxidants (PY and $P G)$ on metal contaminated and uncontaminated MOME is carried out by dosing different concentrations of antioxidants (200,500, 700 and 1000 ppm). For the metal contaminated MOME; 2 ppm concentration of each metal ( $\mathrm{Co}, \mathrm{Cu}, \mathrm{Fe}, \mathrm{Mn}$, and $\mathrm{Ni}$ ) is doped to MOME samples to investigate its influence on the oxidation stability over a long storage period. A constant dosage of metals ( $2 \mathrm{ppm}$ ) is opted in the present study because it is reported elsewhere that the dosage beyond $2 \mathrm{ppm}$ had no significant effect on oxidation stability as it was found to be constant $[4,18]$. To investigate the stability of MOME stored over a long period, the samples of MOME with and without antioxidants and other samples with metal contaminants are stored in $500 \mathrm{ml}$ plastic bottles for six (6) months. Open and closed plastic bottles are used to store the samples and their induction periods are measured monthly to monitor the stability using Rancimat equipment (Model 873 ) as shown in Fig. 1. The average relative humidity and temperature of the room used to store the samples ranges between $30-40 \%$ and $20-25^{\circ} \mathrm{C}$, respectively.

\subsection{Physical and chemical properties determination}

Gas Chromatography Mass Spectrometry (GC-MS), model Agilent $6890 \mathrm{~N}$ is used to determine the composition of MOME as reported in previous works [5, 12]. GC-MS is equipped with a mass selective detector (MSD), Agilent 5973 series. The column used is polyethylene glycol column, PEG (HP Innowax), $60 \mathrm{~m}$ long, $0.25 \mu \mathrm{m}$ film thickness, and $250 \mu \mathrm{m}$ i.d. For each run, $1 \mu \mathrm{L}$ of biodiesel is injected in an autosampler with 200:1 split ratio at 1.7 bars and $250^{\circ} \mathrm{C}$ inlet temperature. During the first $10 \mathrm{~min}$, the oven temperature is maintained at $60^{\circ} \mathrm{C}$, and then increased up to $220^{\circ} \mathrm{C}$ at $4{ }^{\circ} \mathrm{C} / \mathrm{min}$ ramp rate. Thereafter, the temperature is held constant for $10 \mathrm{~min}$ before being increased to $250^{\circ} \mathrm{C}$ at $1{ }^{\circ} \mathrm{C} / \mathrm{min}$ ramp rate. The carrier gas is helium and is used at a constant flow of $1.2 \mathrm{ml} / \mathrm{min}$. Flame ionization detection (FID) is employed to make electronic integration measurements for determination of the percentage composition of individual components. All the relative percentages for each sample are the average value of three experimental runs.

Thermogravimetric analyzer (TGA 2050) is used to estimate thermal oxidation steadiness of MOME samples.. Estimated volumes of the samples ( $\approx 10 \mathrm{mg}$ ) on a partially sealed alumina pan are put into a sampler connected to the instrument (Fig. 1). Unadulterated oxygen is purged at $130 \mathrm{~mL} / \mathrm{min}$ flow rate and the temperature ramped at $10^{\circ} \mathrm{C} / \mathrm{min}$ from room temperature to $500^{\circ} \mathrm{C}$. Upon oxidation, there is a sudden sample weight loss caused by the abstraction of secondary oxidation products. The onset temperature for oxidation is therefore determined by the 


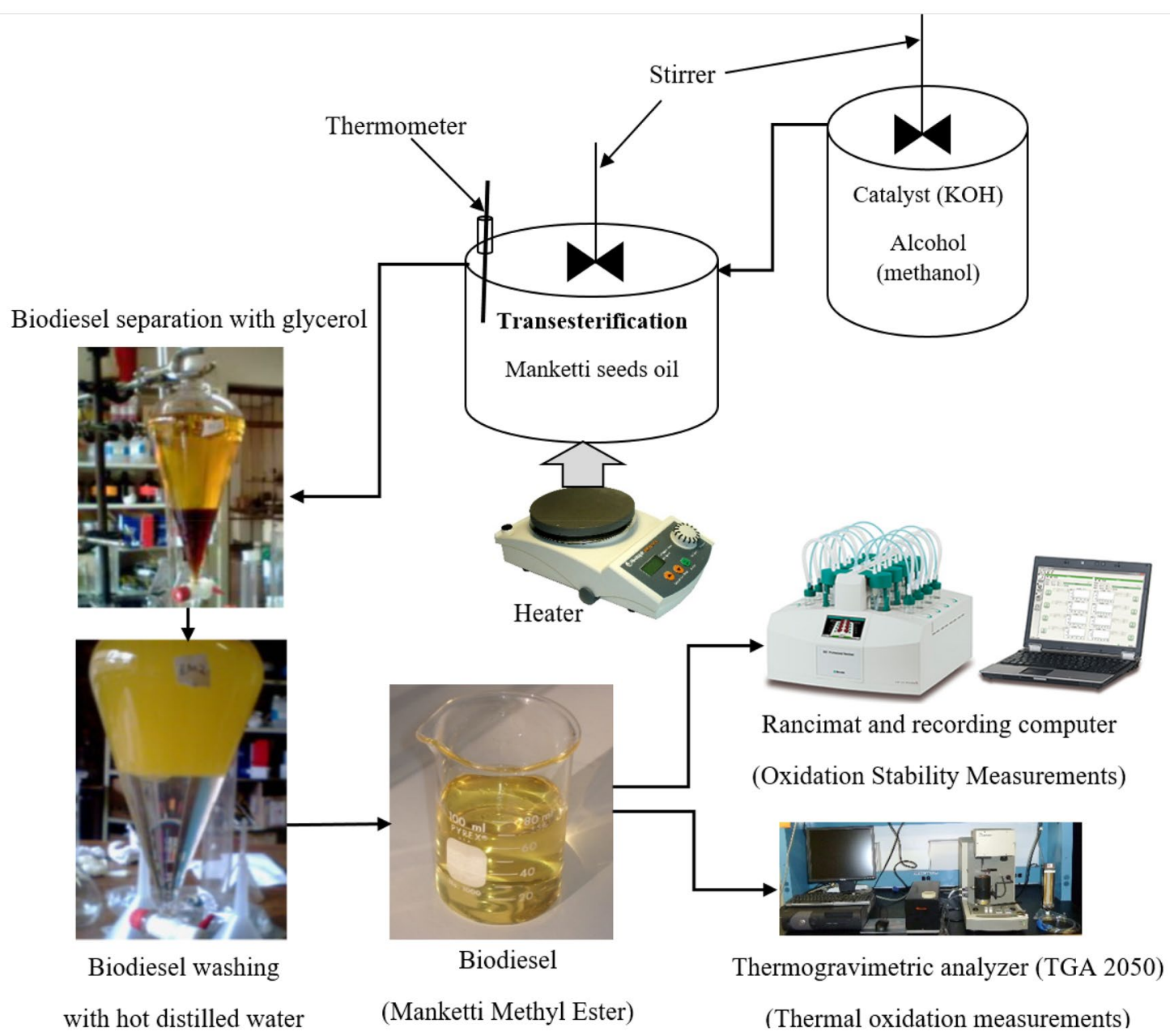

Fig. 1 Experimental set-up (transesterification process, purification of manketti methyl ester and stability measurements)

intersection of the extrapolated baseline and the tangent line of the curve obtained by TGA. To designate the resistance of the biodiesel to thermal degradation, the onset temperature can be habituated [19].

The fuel related properties of MOME are determined using various equipment/instruments as summarized in Table 1. The properties are also compared to diesel and ASTM D6751 and EN14214 biodiesel standards.

\section{Results and discussion}

\subsection{Properties of MOME}

The composition of fatty acids in MOME and its fuel properties are presented in Tables 2 and 3, respectively. The six major fatty acid compounds identified in MOME are Methyl linoleate (C18/2), methyl linolenate (C18/3), methyl oleate (C18/1), methyl stearate (C18/0), methyl palmitate (C16/0), and methyl arachidate (C20/0). MOME contain high polyunsaturated FAME content, which are prone to autoxidation as depicted in Table 2, recording $45.7 \%$ and $21.1 \%$ of methyl linoleate $(\mathrm{C} 18 / 2)$ and methy linolenate (C18/3), respectively. Thus, MOME is one of the unstable biodiesels and can only be stored for an extended period while doped with antioxidants. These results are in good agreement with previous studies $[9,10,12]$. The dominant saturated FAMEs in MOME are the methyl palmitate (C16/0) and stearate (C18/0) which are $10.1 \%$ and $6.6 \%$, respectively.

The essential fuel properties of MOME are within limits specified by global biodiesel standards such as SANS 1935, EN 14214, and ASTM D6751, as shown in Table 3. Freshly-produced MOME showed initial oxidation stability of $4.24 \mathrm{~h}$ well above $3 \mathrm{~h}$ prescribed in the ASTM D6751. It is possibly attributed to the total saturated FAME of $16.9 \%$ and the presence of natural antioxidants. However, this oxidation stability is below the minimum requirement of $8 \mathrm{~h}$ and $6 \mathrm{~h}$, which is laid down in EN 14214 and SANS 1935, respectively. This is possibly due to the high composition

\section{SN Applied Sciences}


Table 1 Fuel related properties determination

\begin{tabular}{llll}
\hline S/n & Property & Equipment/Instrument & Method \\
\hline 1 & Kinematic viscosity & Viscometer (Model TV 4000) & ASTM D445 \\
2 & Cetane number & Waukesha: CFR F5-Engine & ASTM D613 \\
3 & Calorific value & Bomb calorimeter & ASTM D240 \\
4 & Density & Density meter (Model DA-130 N) & ASTM D941 \\
5 & Acid value & & ASTM D974 \\
6 & Cloud point (CP) & & ASTM D2500 \\
7 & Pour point (PP) & & ASTM D97 \\
8 & Cold filter plugging point (CFPP) & Gas chromatography & ASTM D6371 \\
9 & Free and total glycerol & Pensky Marten's flash point tester & ASTM D6584 \\
10 & Flash point & (Stanhope-SETA: 34000-0 U) & \\
& & High-frequency reciprocating ring & ISO 12156 \\
11 & Lubricity & Rancimat equipment (Model 873, & EN 15751 \\
12 & Oxidation stability & Metrohm, Switzerland) & \\
& & &
\end{tabular}

Table 2 Fatty acid compositions of MOME

\begin{tabular}{lc}
\hline Fatty acid composition (wt.\%) & MOME \\
\hline Methyl palmitate (C16/0) & 10.1 \\
Methyl stearate (C18/0) & 6.6 \\
Methyl linoleate (C18/2) & 45.7 \\
Methyl linolenate (C18/3) & 21.1 \\
Methyl oleate (C18/1) & 15.1 \\
Methyl arachidate (C20/0) & 0.2 \\
\hline
\end{tabular}

of monounsaturated (16.2\%) and polyunsaturated (66.8\%) FAME with a tendency to get oxidized [7]. Thus, for more extended storage, MOME must be doped with antioxidants $[7,12,18]$. Besides, MOME recorded convincing cold flow properties which are $\mathrm{CP}\left(-4.9^{\circ} \mathrm{C}\right), \mathrm{CFPP}\left(-9^{\circ} \mathrm{C}\right)$, and PP $\left(-7.5^{\circ} \mathrm{C}\right)$. This is due to the presence of high composition of unsaturated FAME (a total of $83 \%$ ).

\subsection{Influence of antioxidant PY and PG on oxidation stability of MOME}

Figure 2 depicts the influence of antioxidant PY and PG on MOME oxidation stability. The induction period (oxidation stability) rose with increment in antioxidant dosage. PY exhibited better performance than PG; however, both antioxidants recorded induction period above $8 \mathrm{~h}$ with a concentration of $200 \mathrm{ppm}$; fulfilling the minimum requirement of $8 \mathrm{~h}$ and $6 \mathrm{~h}$, outlined in EN 14214 and SANS 1935, respectively. The induction period recorded by $P G$ and $P Y$ at $200 \mathrm{ppm}$ is $8.5 \mathrm{~h}$ and $13 \mathrm{~h}$, respectively. The PY is more superior to PG owing to the possibility that the instantaneous oxidation products of PY still possessed antioxidant properties $[4,7]$. Due to its superiority, antioxidant PY is further used to explore its influence on long-term storage and thermal stability of pure and metal contaminated MOME.
Table 3 Fuel properties of MOME, petroleum-based diesel and biodiesel standards

\begin{tabular}{lclll}
\hline Property $($ Units) & MOME & Diesel & EN 14214 limits & ASTM D6751 limits \\
\hline Density at $15^{\circ} \mathrm{C}\left(\mathrm{Kg} / \mathrm{m}^{3}\right)$ & 877 & 843 & $860-900$ & - \\
Viscosity at $40{ }^{\circ} \mathrm{C}\left(\mathrm{mm}^{2} / \mathrm{s}\right)$ & 4.0 & 2.40 & $3.5-5.0$ & $1.9-6.0$ \\
Acid value $(\mathrm{mg} \mathrm{KOH} / \mathrm{g})$ & 0.12 & - & $0.5 \mathrm{max}$ & $0.5 \mathrm{max}$ \\
Flash point $\left({ }^{\circ} \mathrm{C}\right)$ & 152 & 70 & $>101$ & $130 \mathrm{~min}$ \\
Heating value $(\mathrm{MJ} / \mathrm{kg})$ & 38.15 & 41.98 & - & - \\
Lubricity $(\mu \mathrm{m})$ & 325 & - & - & - \\
Cetane number & 48.5 & 50.53 & 51 min & 47 min \\
Cold filter plugging point $\left({ }^{\circ} \mathrm{C}\right)$ & -9 & - & - & - \\
Cloud point $\left({ }^{\circ} \mathrm{C}\right)$ & -4.9 & -18 & - & Report \\
Pour point $\left({ }^{\circ} \mathrm{C}\right)$ & -7.5 & -22 & - & - \\
Oxidation stability $(\mathrm{h})$ & 4.24 & - & 8 min & $3 \mathrm{~h}$ min \\
Free glycerol $\%(\mathrm{~m} / \mathrm{m})$ & 0.017 & - & 0.02 max & 0.02 max \\
Total glycerol $\%(\mathrm{~m} / \mathrm{m})$ & 0.20 & - & 0.25 max & 0.24 max \\
\hline
\end{tabular}




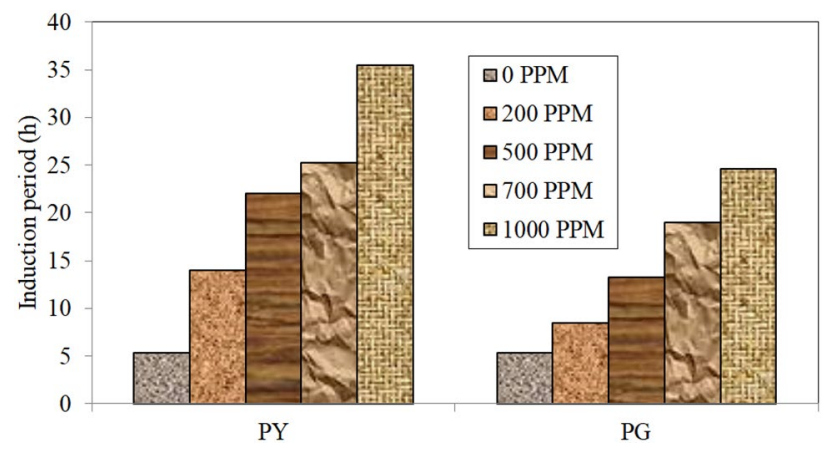

Fig. 2 Influence of PG and PY on oxidation stability of freshly-synthesized MOME
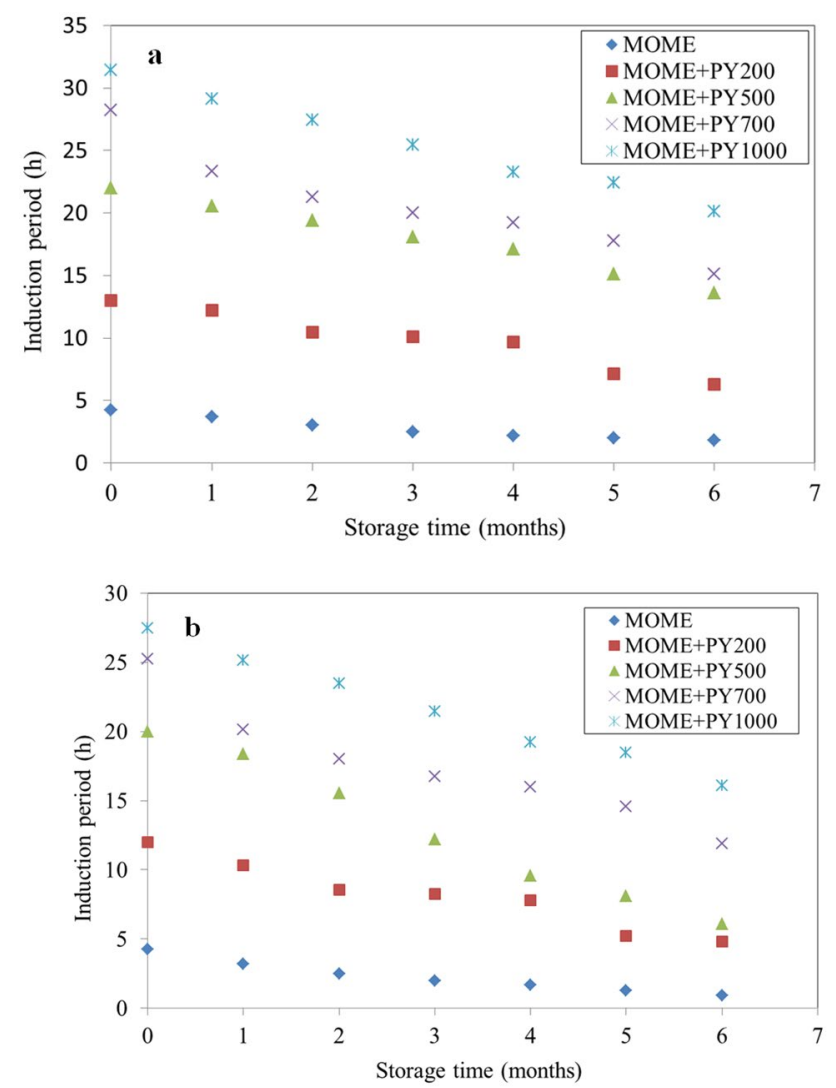

Fig. 3 Influence of antioxidant PY on storage oxidation stability of MOME $\mathbf{a}$ closed plastic bottles and $\mathbf{b}$ open plastic bottles

\subsection{Influence of PY on the long-term storage stability of MOME}

Figure $3 a, b$ show the results for oxidation stability of MOME stored for 6 months in the absence of an antioxidant and at different dosages of antioxidant PY. The result shows that the oxidation stability of MOME without antioxidant decreases drastically with time. The freshly-produced
MOME exhibited oxidation stability of $4.24 \mathrm{~h}$, however, with no antioxidants, samples stored for 6 months in closed and open plastic bottles exhibited reduced oxidation stability of $1.8 \mathrm{~h}$ and $0.9 \mathrm{~h}$, respectively. This observation agrees with earlier research works which reported that biodiesel cannot be stored for a long period of time without antioxidants [18]. It is important to note that treating biodiesel with antioxidants is a promising lowcost method for increasing its resistance to oxidation, the loadings (concentrations) that are kept low between 500 and $1000 \mathrm{ppm}$ are regarded as economically feasible to minimize added costs of biodiesel [20]. Thus, in this study, MOME is doped with antioxidant PY at different loadings (200,500, 700 and 1000 ppm) and stored indoors for 6 months in open and closed bottles. The results indicate that the dosage of antioxidant slowed oxidation by reducing the rate of peroxide formation [7]. The oxidation stability with $200 \mathrm{ppm}$ dosage of antioxidant PY is $6.3 \mathrm{~h}$ in 6 months of storage for the samples in closed bottles while $4.8 \mathrm{~h}$ is the induction period recorded by the samples in bottles left open.

The samples that are stored in open plastic bottles displayed lower oxidation stability as depicted in Fig. 3a, $b$ because MOME is in contact with air that accelerated oxidation of the samples $[5,7,8]$. MOME samples in open plastic bottles displayed oxidation stability of $4.8 \mathrm{~h}, 6.1 \mathrm{~h}$, $11.4 \mathrm{~h}$ and $16.1 \mathrm{~h}$ in 6 months of storage when dosed with 200, 500, 700 and 1000 ppm, respectively. Thus, 500 ppm of antioxidant is required for the samples in open plastic bottles to keep their oxidation stability above $6 \mathrm{~h}$ as per SANS 1935. Samples in closed bottles needed about $200 \mathrm{ppm}$ to record oxidation stability above the minimum limit of $6 \mathrm{~h}$. In the sixth month of storage, the recorded oxidation stability is $6.3 \mathrm{~h}, 13.5 \mathrm{~h}, 15.1 \mathrm{~h}$, and $20.3 \mathrm{~h}$ at the respective dosages of $200,500,700$ and 1000 ppm.

\subsection{Storage stability of MOME containing metal contaminants}

Figures 4 and 5 depict the effects of various metals on MOME oxidation stability in closed and open bottles, respectively, for 6 months. The presence of metals accelerated oxidation of MOME and deteriorated its stability. This results from the formation of free radicals as the metals mediate an initiation reaction between them and the MOME $[4,18,21,22]$. Among the tested metals, $\mathrm{Cu}$ has highly damaging effects on MOME oxidation stability for all samples stored in closed and open bottles followed by $\mathrm{Co}, \mathrm{Mn}$, and $\mathrm{Ni}$ while Fe recorded the least damaging effects. For samples in closed plastic bottles, the oxidation stability of $\mathrm{Cu}$ contaminated MOME is almost zero in the first 3 months of storage in the absence of antioxidant PY, as shown in Fig. 4. In the first month of storage, $\mathrm{Cu}$ 


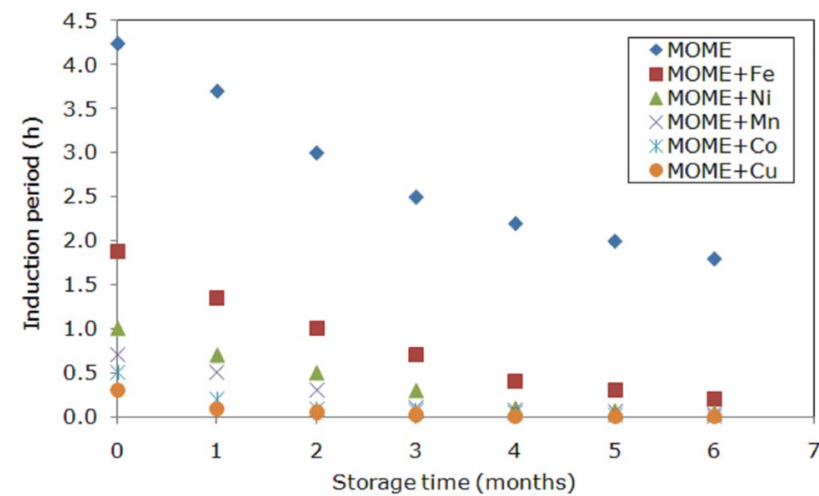

Fig. 4 Oxidation stability for MOME stored in closed plastic bottles with metal contaminants ( 2 ppm each)

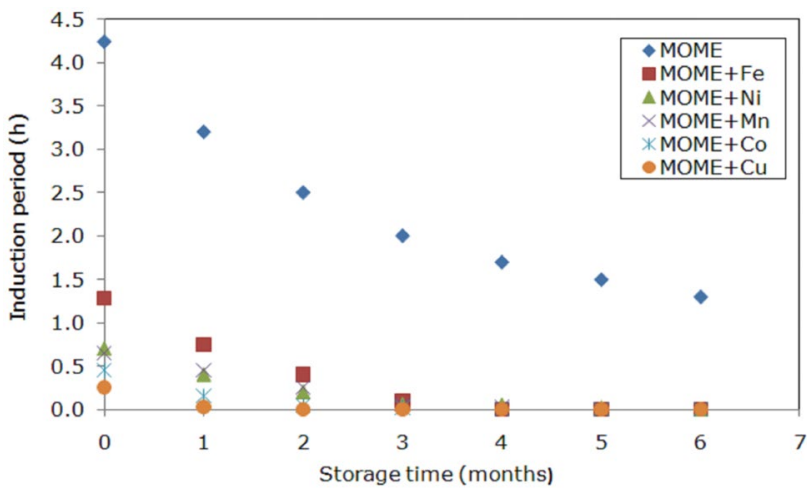

Fig. 5 Oxidation stability for MOME stored in open plastic bottles with metal contaminants ( 2 ppm each)

contaminated MOME samples stored in open bottles displayed zero oxidation stability. This is plausible because the samples are left exposed to the air, hence accelerating MOME oxidation [7, 21,22]. These results agree with previous studies that reported the influence of metals on oxidation stability of biodiesel derived from other feedstocks $[4,8,18,21,22]$. Thus, it can be concluded that biodiesel stability depends on the kind of metals existing on storage containers.

\subsection{Storage stability of metal contaminated MOME dosed with antioxidants}

Figure $6 a, b, c, d$ and e displays the effect of metals on the long-term storage oxidation stability of MOME dosed with PY antioxidant. Experiments to assess the effects of antioxidant additive on MOME storage stability are conducted for samples stored in closed plastic bottles because they displayed convincing oxidation stability. The metal-contaminated samples in open plastic bottles displayed almost zero oxidation stability in the first months
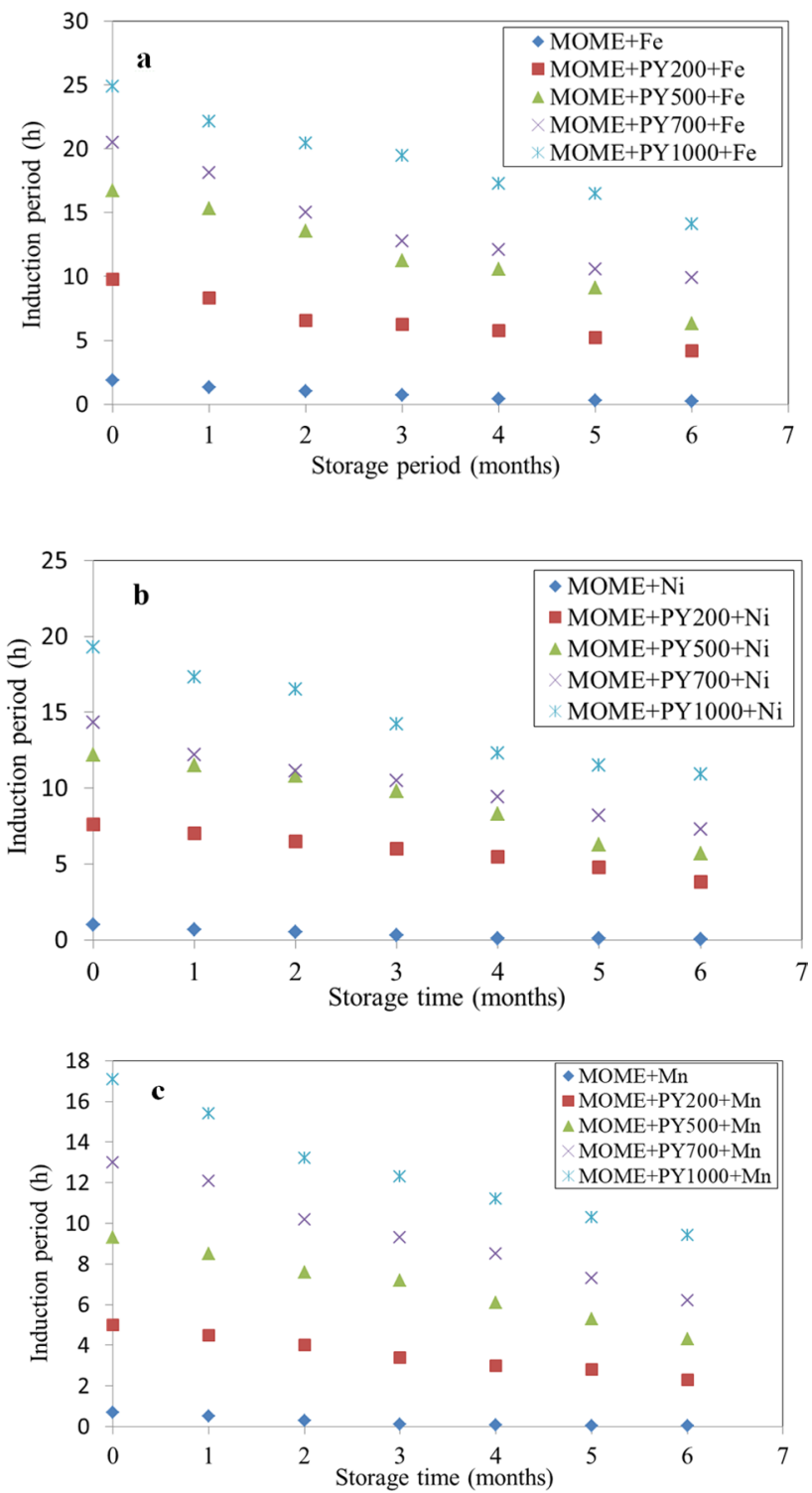

Fig. 6 Influence of PY on storage oxidation stability of MOME contaminated with $2 \mathrm{ppm}$ of a Fe b Ni c $\mathrm{Mn} \mathbf{d} \mathrm{Co}$ and e $\mathrm{Cu}$ in closed plastic bottles

of storage hence are not considered in this analysis. Thus, $500 \mathrm{ml}$ of MOME samples are separately mixed with a constant concentration ( $2 \mathrm{ppm}$ ) of metals ( $\mathrm{Co}, \mathrm{Cu}, \mathrm{Fe}, \mathrm{Mn}$, and $\mathrm{Ni}$ ) and each sample doped with $200,500,7000$, and $1000 \mathrm{ppm}$ of antioxidant PY. The result shows that a dosage of $500 \mathrm{ppm}$ is enough for Fe contaminated MOME to record oxidation stability of $6.2 \mathrm{~h}$ in the sixth month of storage as depicted in Fig. 6a which is above a minimum limit stated in ASTM D6751 (3 h) and SANS 1935 (6 h). In general, Fe exhibited the least damaging effects on MOME oxidation stability compared to other studied metals.

Figure $6 \mathrm{~b}, \mathrm{c}$ show that $700 \mathrm{ppm}$ of $\mathrm{PY}$ is adequate for $\mathrm{Ni}$ and Mn contaminated MOME to exhibit oxidation stability 

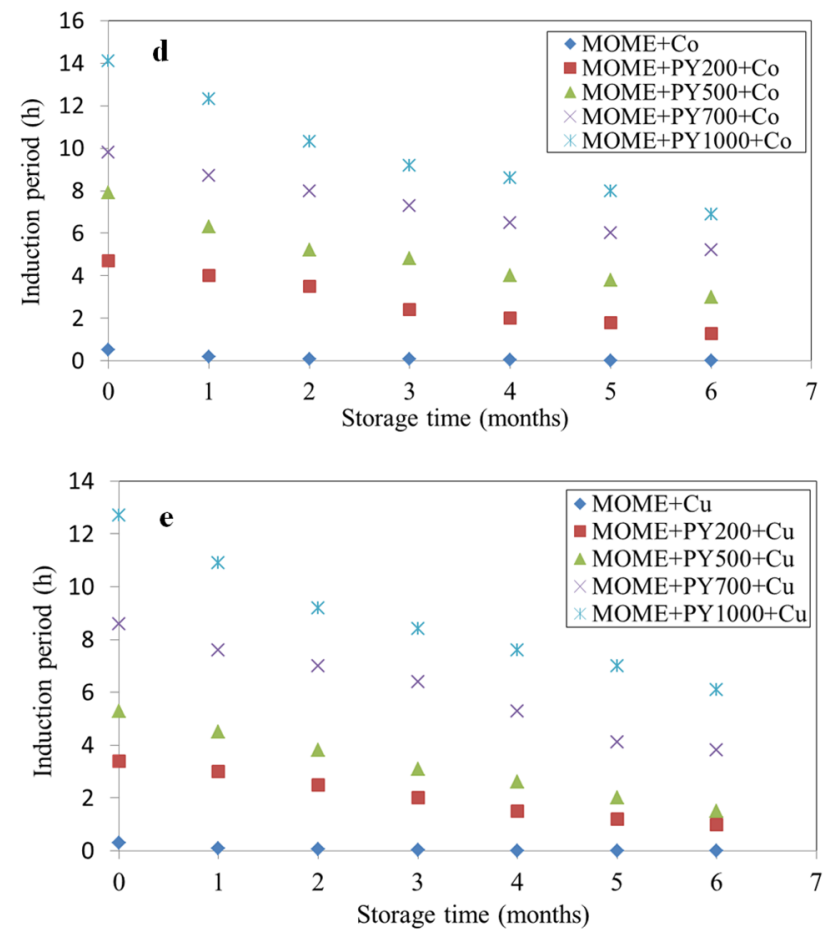

Fig. 6 (continued)

above $6 \mathrm{~h}$ for 6 months of storage. Ni contaminated MOME $(\mathrm{MOME}+\mathrm{PY} 700+\mathrm{Ni})$ recoded oxidation stability of $7.3 \mathrm{~h}$ in the sixth month of storage while fresh produced MOME with $700 \mathrm{ppm}$ of antioxidant PY and $2 \mathrm{ppm}$ of $\mathrm{Ni}$ displayed oxidation stability of $14.5 \mathrm{~h}$. Mn contaminated MOME (MOME + PY700 + Mn) exhibited oxidation stability of $6.2 \mathrm{~h}$ in the sixth month of storage while fresh Mn contaminated MOME with $700 \mathrm{ppm}$ PY antioxidant recorded oxidation stability of $13 \mathrm{~h}$. Figure $6 \mathrm{~d}$, e respectively, depict how the storage oxidation stability of MOME is influenced by $\mathrm{Co}$ and $\mathrm{Cu}$. The results indicate that $\mathrm{Co}$ and $\mathrm{Cu}$ contaminated MOME needed PY dosage of $1000 \mathrm{ppm}$ to exhibit oxidation stability above $6 \mathrm{~h}$ to fulfil limit outlined in ASTM D6751 ( $3 \mathrm{~h}$ ) and SANS 1935 (6 h) but are below EN 14214 ( $8 \mathrm{~h}$ ) for 6 months of storage. Co contaminated MOME $(\mathrm{MOME}+\mathrm{PY} 1000+\mathrm{Co})$ recorded induction period of $6.9 \mathrm{~h}$ in the sixth month of storage while fresh Co contaminated MOME with PY dosage of 1000 ppm displayed oxidation stability of $14.1 \mathrm{~h}$. Cu contaminated MOME (MOME + PY1000 + Cu) exhibited induction period of $6.1 \mathrm{~h}$ in the sixth month of storage, and the fresh Cu contaminated MOME with $1000 \mathrm{ppm}$ of PY recoded an induction period of $12.5 \mathrm{~h}$. It can be seen from the results that metal contaminated MOME exhibited decreasing oxidation stability with time; however, the addition of antioxidant PY slowed the oxidation process. These findings concur with previous studies that reported the effect of selected metal contaminants on the stability of biodiesel and concluded that $\mathrm{Co}$ and $\mathrm{Cu}$ had higher catalytic effects on oxidation stability of biodiesels [18, 21-23].

\section{Thermal stability of MOME}

In this study, Thermogravimetric Analysis (TGA) is used to assess thermal stability of MOME. TGA method is used to evaluate the relative weight loss of a sample as the temperature rises. Thermal instability concerns a more rapid rate of oxidation at elevated temperatures. This increases the weight of the molecules owing to the formation of insoluble [24-26]. TGA determines the temperature at which oxidation reactions occur and it is referred to as oxidation onset temperature. There is no specific standard prescribing minimum limit of thermal stability of biodiesel; however, it is reported elsewhere in the literature that biodiesel recording thermal stability above $150^{\circ} \mathrm{C}$ is regarded as thermally stable [5]. The TG curve as depicted in Fig. 7 shows percentage mass loss against temperature rise (in which the readings of remaining mass of the sample are recorded and plotted against temperature rise). DTG curve indicates the rate at which the mass of the sample is lost, it is defined as the derivative curve from TG, in which the area under the peak is proportional to the sample mass loss [24]. Thermal steadiness and volatility characteristics of MOME or any biofuel are critical parameters for determining lubricity properties and ignition quality [25].

MOME recorded oxidation onset temperature of $211.33^{\circ} \mathrm{C}$ as depicted in Fig. 7, an indication that MOME is thermally stable [5]. The first derivative (DTG) curve in Fig. 7 shows at least two thermal events occurred, i.e. oxidation followed by thermal degradation. The highest degradation rate of MOME is observed at the temperature of $300^{\circ} \mathrm{C}$, whereby weight loss of MOME increased to the maximum while at higher temperatures the weight loss decreased. The curve flattered at a temperature above $400^{\circ} \mathrm{C}$, an indication that no further conversion is happening. The changes in weight happened because of evaporation and/or combustion of MOME, especially oleate, linoleate and linolenate, which are plentiful in MOME (Table 1). Addition of antioxidants and metal contaminants (Fe) influenced the onset temperature of MOME. Fe contaminated MOME is further investigated for thermal stability because it displayed the most minimal effects on the stability of MOME as compared to the other studied metals. The onset temperature of MOME improved with a dosage of antioxidant PY, but decreased on the addition of $2 \mathrm{ppm}$ of Fe as depicted in Table 4. The onset temperature of pure MOME increased from $211^{\circ} \mathrm{C}$ to $215,218,220$ and $225^{\circ} \mathrm{C}$ when dosed with $200,500,700$ and 1000 ppm of antioxidant PY, respectively. Contaminating MOME with $2 \mathrm{ppm}$ of Fe decreased the onset temperature from $211^{\circ} \mathrm{C}$ to $201^{\circ} \mathrm{C}$. However, doping Fe contaminated MOME with antioxidant 
Fig. 7 Thermogravimetric (TG) and differential thermogravimetric (DTG) curves of MOME

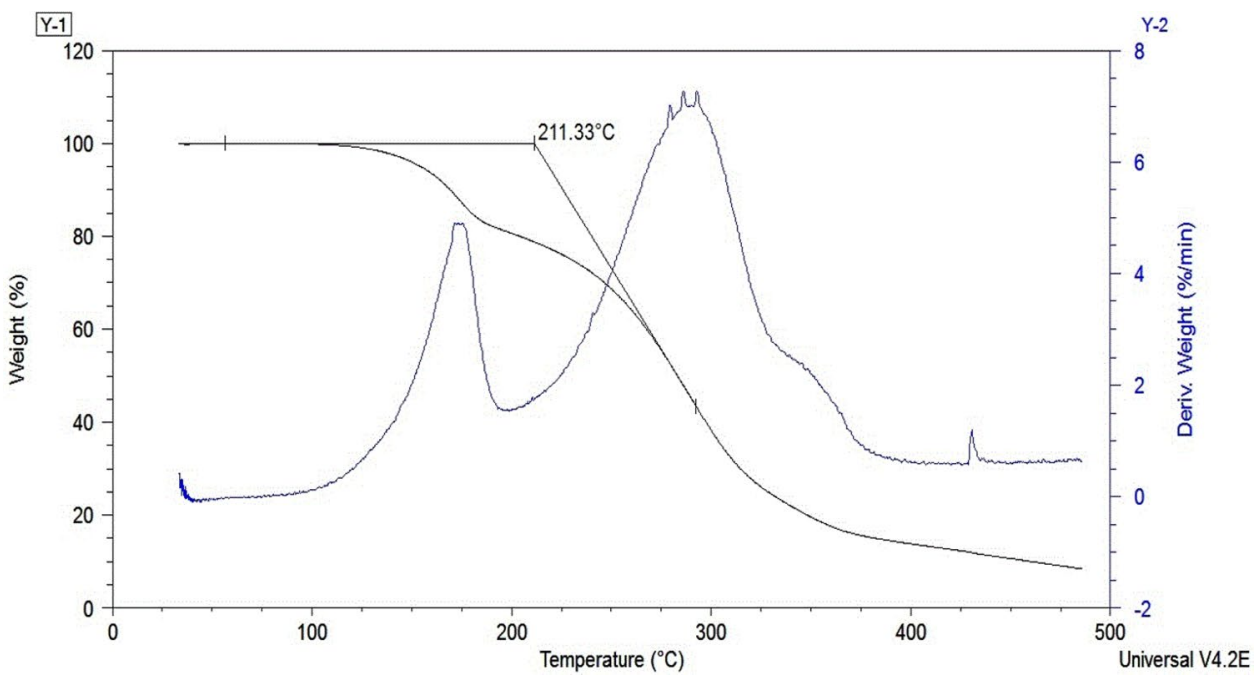

Table 4 TGA analysis of MOME with antioxidant additive and metal contaminants

\begin{tabular}{|c|c|}
\hline Sample name & $\begin{array}{l}\text { Onset } \\
\text { temperature } \\
\left({ }^{\circ} \mathrm{C}\right)\end{array}$ \\
\hline MOME & 211 \\
\hline MOME + PY (200 ppm) & 215 \\
\hline MOME + PY (500 ppm) & 218 \\
\hline MOME + PY (700 ppm) & 220 \\
\hline MOME + PY (1000 ppm) & 225 \\
\hline $\mathrm{MOME}+2 \mathrm{ppm}$ of Fe & 201 \\
\hline $\mathrm{MOME}+\mathrm{PY}(200 \mathrm{ppm})+2 \mathrm{ppm}$ of $\mathrm{Fe}$ & 205 \\
\hline $\mathrm{MOME}+\mathrm{PY}(500 \mathrm{ppm})+2 \mathrm{ppm}$ of $\mathrm{Fe}$ & 207 \\
\hline $\mathrm{MOME}+\mathrm{PY}(700 \mathrm{ppm})+2 \mathrm{ppm}$ of $\mathrm{Fe}$ & 211 \\
\hline $\mathrm{MOME}+\mathrm{PY}(1000 \mathrm{ppm})+2 \mathrm{ppm}$ of $\mathrm{Fe}$ & 215 \\
\hline
\end{tabular}

PY it improved the onset temperature from $201{ }^{\circ} \mathrm{C}$ to 205 , 2017, 211 and $2015^{\circ} \mathrm{C}$ when dosed with 200, 500, 700 and 1000 ppm of antioxidant PY, respectively. These results are in good agreement with reports by Jain and Sharma [26] and Wan Nik et al. [27] who studied the effect of antioxidants on the thermal stability of biodiesels made from Jatropha curcas and palm oils, respectively. The dosage of antioxidant PY to MOME samples without and with metal contaminants reduced formation of hydrogen-free radicals and hence improved thermal stability. From the results above, it can be concluded that PY acted as an oxidation inhibitor [7, 23].

\section{Conclusion}

This research work investigates the influence of antioxidant additives and metal contaminants on the long-term storage stability of MOME. Thermal stability of MOME in presence or absence of antioxidant PY are also carried out. The characterization results show that most of the essential fuel properties are within limits laid down in EN 14214, SANS 1935, and ASTM D 6751 biodiesel standards; hence biodiesel derived from manketti seeds oil of Southern African origin can be utilized as a partial substitute for petrodiesel without major engine modifications. The most superior properties of MOME are the cold flow properties which are $\mathrm{CP}\left(-4.9^{\circ} \mathrm{C}\right), \mathrm{PP}\left(-7.5^{\circ} \mathrm{C}\right)$ and CFPP $\left(-9^{\circ} \mathrm{C}\right)$ and oxidation stability of $4.24 \mathrm{~h}$ fulfilling the minimum $3 \mathrm{~h}$ value outlined in ASTM D6751. However, the oxidation stability result fails the EN 14214 $(8 \mathrm{~h})$ and SANS 1935 (6 h) standards. Among antioxidants tested on oxidation stability of MOME, PY is superior to PG. However, a dosage of $200 \mathrm{ppm}$ is enough for both PG and PY to record oxidation stability of $8.5 \mathrm{~h}$ and $13 \mathrm{~h}$, respectively, fulfilling EN 14214, SANS 1935, and ASTM D 6751 standards. The result of analysis of long-term storage stability of MOME containing antioxidant PY indicates that, a dosage of $200 \mathrm{ppm}$ of antioxidant PY is enough for MOME to record oxidation stability of $6.3 \mathrm{~h}$ above ASTM D 6751(3 h) in the sixth month of storage for the samples stored in the closed plastic bottles, while $4.8 \mathrm{~h}$ is the induction period exhibited by the samples stored in the open plastic bottles. Investigations on metal contaminants with MOME show that metals influenced the oxidation stability of MOME. The induction period decreased drastically when MOME is contaminated with metals. Among the tested metals, $\mathrm{Cu}$ has the highest catalytic effects. Besides, MOME recorded excellent thermal stability of $211.33^{\circ} \mathrm{C}$. Although long-term storage stability of MOME is enhanced by adding PY or PG antioxidants, further research are still needed on economic assessment to justify the cost of overall products.

Acknowledgement The authors acknowledge funds from The World Academy of Sciences (TWAS) with ref. no. 17-495 RG/CHE/AF/AC_G 
- FR3240297727 for purchasing equipment used for oxidation stability tests.

\section{Compliance with ethical standards}

Conflict of interest I declare no conflict of interest in this work.

\section{References}

1. Renewable Energy Policy Network for the 21 st Century (REN21) Global Report. 2016

2. Karmakar B, Halder G (2019) Progress and future of biodiesel synthesis: advancements in oil extraction and conversion technologies, Energy Convers. Manag 182:307-339. https://doi. org/10.1016/j.enconman.2018.12.066

3. Hasan MM, Rahman MM (2017) Performance and emission characteristics of biodiesel-diesel blend and environmental and economic impacts of biodiesel production: a review. Renew Sustain Energ 74:938-948. https://doi.org/10.1016/j. rser.2017.03.045

4. Kivevele T, Huan Z (2015) Influence of metal contaminants and antioxidant additives on storage stability of biodiesel produced from non-edible oils of Eastern Africa origin (Croton megalocarpus and Moringa oleifera oils). Fuel 158:530-537. https://doi. org/10.1016/j.fuel.2015.05.047

5. Kivevele TT, Mbarawa MM, Bereczky A, Laza T, Madarasz J (2011) Impact of antioxidant additives on the oxidation stability of biodiesel produced from Croton Megalocarpus oil. Fuel Process Technol 92:1244-1248. https://doi.org/10.1016/j.fupro c.2011.02.009

6. Kumar N (2017) Oxidative stability of biodiesel: causes, effects and prevention. Fuel 190:328-350. https://doi.org/10.1016/j. fuel.2016.11.001

7. Adu-Mensah D, Mei D, Zuo L, Zhang Q, Wang J (2019) A review on partial hydrogenation of biodiesel and its influence on fuel properties. Fuel 251:660-668. https://doi.org/10.1016/j. fuel.2019.04.036

8. Yaakob Z, Narayanan BN, Padikkaparambil S, Unni KS, Akbar PM (2014) A review on the oxidation stability of biodiesel. Renew Sustain Energy Rev 35:136-153. https://doi.org/10.1016/j. rser.2014.03.055

9. Cheikhyoussef N, Kandawa-Schulz M, Böck R, de Koning C, Cheikhyoussef A, Hussein AA (2018) Characterization of Schinziophyton rautanenii (Manketti) nut oil from Namibia rich in conjugated fatty acids and tocopherol. J Food Compos Anal 66:152-159. https://doi.org/10.1016/j.jfca.2017.12.015

10. Juliani HR, Koroch AR, Simon JE, Wamulwange C (2007) Mungongo cold pressed oil (Schinziophyton rautanenii): a new natural product with potential cosmetic applications. ISHS Acta Hortic 756:407-412

11. Atabani AE, Mofijur M, Masjuki HH, Badruddin IA, Chong WT, Cheng SF, Gouk SW (2014) A study of biodiesel production and characterization of Manketti (Ricinodendron rautonemii) methyl ester and its blends as a potential biodiesel. Biofuel Res J 4:139-146

12. Kivevele TT, Huan $Z$ (2015) An analysis of fuel properties of fatty acid methyl ester from Manketti seeds oil. Int J Green Energy 12:291-296. https://doi.org/10.1080/15435075.2014.886579

13. Rutto HL, Enweremadu CC (2011) Optimization of production variables of biodiesel from manketti using response surface methodology. Int J Green Energy 8:768-779. https:// doi.org/10.1080/15435075.2011.600375

14. Zhang J, Lu M, Ren F, Knothe G, Tu Q (2019) A greener alternative titration method for measuring acid values of fats, oils, and grease. J Am Oil Chem Soc 99(10):1083-1091. https://doi. org/10.1002/aocs.12281

15. Kivevele TT, Mbarawa MM (2010) Comprehensive analysis of fuel properties of biodiesel from croton megalocarpus oil. Energy Fuels 24:6151-6155. https://doi.org/10.1021/ef100880g

16. Kafuku G, Lam MK, Kansedo J, Lee KT, Mbarawa M (2010) Heterogeneous catalyzed biodiesel production from Moringa oleifera oil. Fuel Process Technol 91:1525-1529. https://doi. org/10.1016/j.fuproc.2010.05.032

17. Kafuku G, Lam MK, Kansedo J, Lee KT, Mbarawa M (2010) Croton megalocarpus oil: a feasible non-edible oil source for biodiesel production. Bioresour Technol 101:7000-7004. https://doi. org/10.1016/j.biortech.2010.03.144

18. Singh M, Singh DK, Gandhi SK et al (2019) Effect of metal contaminants and antioxidants on the oxidation stability of argemone mexicana biodiesel: experimental and statistical study. Waste Biomass Valor. https://doi.org/10.1007/s12649-019-00886 $-5$

19. Kivevele $T$, Zhongjie $H$ (2013) Effects of antioxidants on the cetane number, viscosity, oxidation stability, and thermal properties of biodiesel produced from nonedible oils. Energy Technol 1:537-543. https://doi.org/10.1002/ente.201300072

20. Dunn RO (2008) Antioxidants for improving storage stability of biodiesel. Biofuels Bioprod. Bioref 2:304-318

21. Jain S, Sharma MP (2013) Effect of metal contaminants and antioxidants on the storage stability of Jatropha curcas biodiesel. Fuel 109:379-383. https://doi.org/10.1016/j.fuel.2013.03.050

22. Jain S, Sharma MP (2011) Long term storage stability of Jatropha curcas biodiesel. Energy 36:5409-5415. https://doi. org/10.1016/j.energy.2011.06.055

23. Singh M, Singh DK, Gandhi SK, Sarin A, Saini S, Mahla SK, Gupta A, Sandhu SS (2019) Effect of metal contaminants and antioxidants on the oxidation stability of Argemone mexicana biodiesel: experimental and statistical study. Waste Biomass Valor. https:// doi.org/10.1007/s12649-019-00886-5

24. Freire LMS, Bicudo TC, Rosenhaim R, Sinfrônio FSM, Botelho JR, Carvalho Filho JR et al (2009) Thermal investigation of oil and biodiesel from Jatropha curcas L. JTherm Anal Calorim 96:1029_ 1033. https://doi.org/10.1007/s10973-009-0055-y

25. de Souza MC, de Souza Gonçalves JF, Gonçalves PC, Lutif SYS, de Oliveira Gomes J (2019) Use of Jatropha and Moringa oils for lubricants: metalworking fluids more environmental-friendly. Ind Crops Prod 129:594-603. https://doi.org/10.1016/j.indcr op.2018.12.033

26. Jain S, Sharma MP (2012) Application of thermogravimetric analysis for thermal stability of Jatropha curcas biodiesel. Fuel 93:252-257. https://doi.org/10.1016/j.fuel.2011.09.002

27. Wan Nik WB, Ani FN, Masjuki HH (2005) Thermal stability evaluation of palm oil as energy transport media. Energy Convers Manag 46:2198-2215. https://doi.org/10.1016/j.encon man.2004.10.008

Publisher's Note Springer Nature remains neutral with regard to jurisdictional claims in published maps and institutional affiliations. 